\title{
Bone marrow blood vessels: normal and neoplastic niche
}

\author{
Saeid Shahrabi, ${ }^{1}$ Hadi Rezaeeyan, ${ }^{2}$ Ahmad Ahmadzadeh, ${ }^{3}$ Mohammad Shahjahani, ${ }^{2}$ \\ Najmaldin Saki ${ }^{3}$ \\ 1 Department of Biochemistry and Hematology, Semnan University of Medical Sciences, Semnan; \\ ${ }^{2}$ Golestan Hospital Clinical Research Development Unit, Ahvaz Jundishapur University of Medical \\ Sciences, Ahvaz; ${ }^{3}$ Health Research Institute, Research Center of Thalassemia \& Hemoglobinopathy, \\ Ahvaz Jundishapur University of Medical Sciences, Ahvaz, Iran
}

\begin{abstract}
Blood vessels are among the most important factors in the transport of materials such as nutrients and oxygen. This study will review the role of blood vessels in normal bone marrow hematopoiesis as well as pathological conditions like leukemia and metastasis. Relevant literature was identified by a Pubmed search (1992-2016) of English-language papers using the terms bone marrow, leukemia, metastasis, and vessel. Given that blood vessels are conduits for the transfer of nutrients, they create a favorable situation for cancer cells and cause their growth and development. On the other hand, blood vessels protect leukemia cells against chemotherapy drugs. Finally, it may be concluded that the vessels are an important factor in the development of malignant diseases.
\end{abstract}

\section{Introduction}

Self-renewal, quiescence, and differentiation of hematopoietic stem cells (HSCs), as well as differentiation of progenitor cells, are dependent upon the interaction between these cells with bone marrow (BM)

Correspondence: Najmaldin Saki, Health research institute, Research Center of Thalassemia \& Hemoglobinopathy, Ahvaz Jundishapur University of Medical Sciences, Ahvaz, Iran.

E-mail: najmaldinsaki@gmail.com

Key words: Bone marrow; niche; vessel.

Acknowledgements: we wish to thank all our colleagues in Golestan Hospital, Ahvaz Jundishapur University of Medical Sciences.

Conflict of interest: the authors declare that they have no conflict of interest.

Received for publication: 3 August 2016.

Revision received: 11 November 2016.

Accepted for publication: 17 November 2016.

This work is licensed under a Creative Commons Attribution NonCommercial 4.0 License (CC BY-NC 4.0).

(C) Copyright S. Shahrabi et al., 2016

Licensee PAGEPress, Italy

Oncology Reviews 2016; 10:306

doi:10.4081/oncol.2016.306 microenvironment. BM microenvironment includes a variety of cells, including stromal cells (mesenchymal stem cells, osteoblasts, etc). These cells affect the proliferation and differentiation of HSCs via secretion or expression of chemokines, adhesion molecules as well as membrane and secretory factors. ${ }^{1,2}$ BM stroma components are organized in a special environment known as niche. The term "hematopoietic stem cell niche" was described by Schofield in 1978 as the microenvironment maintaining the stem cells and preventing their differentiation.$^{3}$ In BM, there are two niches: endosteal and vascular, which are different molecularly and cellularly. HSCs are quiescent in endosteal niche in which different cells such as CXCL12-abundant reticular (CAR) cells, megakaryocytes and spindle-shaped $\mathrm{N}$-cadherin+, CD45 neg osteoblastic cells are present. ${ }^{4,5}$ There is controversy with respect to the cells that are involved in generation of quiescence in HSCs. For example, some studies suggest the CXCL4 secreted from megakaryocytes and some $\mathrm{N}$-cadherin+ cells as the main factors in this regard. ${ }^{6}$ There is a site known as vascular niche in BM that includes various types of vessels such as arteries, arterioles, capillaries and sinusoids, which are relatively different in terms of surface markers and function. Blood vessels are involved in the transport of cells, nutrients, oxygen and waste products. They are also involved in HSCs homeostasis and regeneration of body organs without causing fibrosis via production of angiocrine factors such as vascular endothelial growth factor (VEGF) and fibroblast growth factor (FGF), which are secreted by blood vessel endothelial cells. ${ }^{7,8}$ It has been stated that these vessels together with local mesenchymal stem cells (MSCs) make up a site known as perivascular niche where HSCs are located. MSCs are involved in the proliferation and differentiation of HSCs via secretion of stem cell factor (SCF) and CXCL12. ${ }^{9}$ Blood vessels support cancer cells in the same way that they protect early HSCs in BM. Cancer cells bind endothelial cells (ECs) through cell-to-cell communications, retaining the cancer cells in quiescence phase. In addition, the transport of oxygen and nutrients from blood vessels to cancer cells results in growth and survival of these cells. ${ }^{10}$ In this paper, we examine the role of blood vessels in control of hematopoiesis in normal conditions and consider their role in hematopoietic malignancies and metastasis.

\section{The vessel in normal bone marrow}

During development process, HSCs reside in aortic gonad mesonephros (AGM), yolk sac, placenta, fetal liver, spleen and BM, respectively. ${ }^{11}$ In BM, the Interaction between MSCs, osteoblasts, osteoclasts, fibroblasts, adipocytes and endothelial cells is essential for HSCs maintenance and hematopoiesis. ${ }^{12} \mathrm{HSCs}$ in BM are often located in endosteal niche and vascular niche in which HSCs are in quies- 
cence and proliferation state, respectively. The quiescence state enables HSCs to replenish BM and causes their storage in BM to be protected against mutations leading to malignancy. ${ }^{13,14} \mathrm{BM}$ microenvironment includes a series of vessel organized in a specific order. The arteries are longitudinally aligned along the diaphysis of long bones and infiltrate into BM via branching to small arterioles. The arterioles progress into endosteal region in BM and at the same time undergo thinning. The sinusoids lie close to endosteal region following arterioles and have a dimeter higher than arteries and arterioles. ${ }^{15,16}$ These sinusoids form a capillary network with venoussinusoids and the latter converge to a central sinus in BM center. ${ }^{17}$ There are two capillary types in long bones as the site of hematopoiesis in adults: $\mathrm{L}$ and $\mathrm{H}$, which are different in terms of function, surface marker expression and structure. ${ }^{18}$ The $\mathrm{H}$ type expresses a higher level of CD31 in comparison with $\mathrm{L}$ type. The $\mathrm{H}$ type plays an important role in angiogenesis and is thus subject to increased proliferation during regeneration. ${ }^{19}$

The non-myelinating Schwann cells lie parallel to arterioles. ${ }^{1,20}$ Sinusoids are surrounded by stromal cells bearing leptin receptor (LepR). A high level of c-kit and CXCL-12 is expressed on LepR ${ }^{+}$stromal cells. Elimination of these molecules from the surface of LepR ${ }^{+}$ cells results in BM depletion from quiescent HSCs; therefore, LepR+ cells are involved in the maintenance and survival of HSCs. ${ }^{21}$ Megakaryocytes bind VCAM-1 in sinusoid EC through VLA-4 adhesion molecule, an interaction leading to platelet production and release from BM. These platelets contain a series of angiogenesis stimulating factors within their granules that are involved in angiogenesis. ${ }^{22,23}$ Blood vessels are involved in oxygen transport to various body organs including BM. Given the presence of blood vessels in BM microenvironment, oxygen concentration in BM is $1-6 \%$, which is too low but is higher than the concentration required to initiate hypoxic responses. Oxygen concentration is in its maximum (6\%) around sinusoids while the lowest oxygen concentration (1\%) is observed in endosteal region. $7,24,25$ Reactive oxygen species (ROS) are the factors derived from reduction of molecular oxygen, which are involved in the regulation and differentiation of hematopoiesis process and thus result in HSCs proliferation and differentiation. ${ }^{26}$ The permeability and traffic of cells near arterioles is lower than sinusoids due to structures called VE-cadherin. Cellular metabolism of arterioles is based on glycolysis according to oxygen concentration and the blood flow rate in arterioles is much higher compared with sinusoids. These and other factors considerably reduce the formation of ROS in the vicinity of arteriole relative to sinusoids; therefore, the proliferation and differentiation of HSCs is increased due to formation of ROS near sinusoids. ${ }^{27}$ Increase in ROS along with the activation of P38-MAPK and mTOR pathways inactivates PTEN and maintains AKT in an active state such that HSCs lose their self-renewal state and begin differentiation. ${ }^{28}$ In terms of structural and surface markers, arterioles show differences with sinusoids. Arterioles are characterized by VEGFR- 3 VEGFR- ${ }^{+}$Sca- $1^{+}$while sinusoids show Sca-1- VEGFR-3+ ${ }^{+}$, and VEGFR-2+ ${ }^{+}$. These vessels are involved in the regulation of hematopoiesis through their surface markers as well as release of a number of factors (Table 1). ${ }^{29-55}$ From the above statements, it can be concluded that HSCs in BM are mostly located in the vicinity of arterioles and sinusoids. These vascular ducts are different in terms of morphology and their surrounding conditions, which would differently affect HSCs that are eventually observed in different conditions in terms of oxygen concentration, glycolysis and blood flow rate.

\section{The vessel and angiogenesis in leukemia}

Since chemotherapy is a common approach for treatment of leukemia patients, the majority of leukemia cells are eliminated with this method and nearly $30-70 \%$ of patients will die of their disease relapse. ${ }^{56}$ Like other resident stem cells in BM, leukemia cells are associated with BM microenvironment, which provides a safe and proper place for their growth and survival. The level of multi-drug resistance (MDR) molecules such as p-glycoprotein is increased on leukemic cells, which leads to the resistance of leukemia cells to chemotherapy and disease relapse. ${ }^{57-59}$ The exterior environment of leukemia cells is rich in blood vessels and increasing angiogenesis is associated with poor prognosis. ${ }^{60}$ Consolidation and integrity of ECs, which is regulated by microtubules (important components of cytoskeleton), plays a key role in the exchange of materials into and out of vessels, preventing the penetration of chemotherapy drugs into vessels. ${ }^{61}$ Therefore, targeting the microtubules by drugs and disintegration of ECs causes permeation

Table 1. Arteriole and sinusoid vesselfactors involved in hematopoiesis regulation.

\begin{tabular}{|c|c|c|c|c|}
\hline Factor & Chro. & Function & Leukemia & References \\
\hline VEGFR-2 & $4 q 12$ & Recovery and reconstitution of HSCs & $\begin{array}{l}\text { Up regulation. } \\
\text { AKT phosphorylation. } \\
\text { Apoptosis inhibition. } \\
\text { Induces drugresistance. }\end{array}$ & $29-31$ \\
\hline SCF & $12 \mathrm{q} 22$ & Maintenance of HSCs & $\begin{array}{l}\text { Up regulation. } \\
\text { Leukemic cells growth. }\end{array}$ & $32-35$ \\
\hline E-selectin & $1 q 24-25$ & Promotesthe proliferation of HSCs & $\begin{array}{l}\text { Survival of leukemic cells. } \\
\text { Migration of leukemic cells to another location }\end{array}$ & $36-38$ \\
\hline NO & $7 \mathrm{q} 35-36$ & Differentiation to myeloid progenitors & Induces apoptosis in leukemia cells. & $39-41$ \\
\hline CXCL-12 & $10 \mathrm{q} 11$ & Maintenance of HSCs & $\begin{array}{l}\text { Up regulation. } \\
\text { Survival and proliferation of leukemia cells }\end{array}$ & $42-45$ \\
\hline DLL1,4 (Notch ligand) & $6 q 2715 q 21.1$ & $\begin{array}{l}\text { Expansion and exhaustionprevention } \\
\text { of HSCs }\end{array}$ & Unfavorable prognosis. & $46-49$ \\
\hline Jagged-1 & 20p12 & Regenerative of HSCs & $\begin{array}{l}\text { Up regulation. } \\
\text { Favorable prognosis. }\end{array}$ & $50-52$ \\
\hline Pleiotrophin & $7 \mathrm{q} 33$ & Expansion and retention of HSCs & $\begin{array}{l}\text { Up regulation. } \\
\text { Poor prognosis. }\end{array}$ & $53-55$ \\
\hline
\end{tabular}

VEGFR-2, vascular endothelial growth factor-2; HSC, hematopoietic stem cell; SCF, stem cell factor; E-selectin, endothelial selectin; CXCL-12, C-X-C motif chemokine 12; NO, nitric oxide; DLL, delta-like ligand. 
of blood vessels to chemotherapy agents as well as susceptibility of vessels to these drugs, which can prevent the proliferation and expansion of leukemia cells. ${ }^{60}$ Leukemia cells release a cytokine known as tumor necrosis factor (TNF- $\alpha$ ) that activates ECs, which express adhesion molecules such as VCAM-1, ICAM-1 (P-and E-selectin) on their surface upon activation, resulting in binding of myoblast cells to ECs. This interaction is involved in resistance of leukemia cells to chemotherapy .62 When leukemia cells integrate into ECs, Rac-1GTPase is activated in them and affects p21, p17, and p57 factors. The expression of these molecules causes leukemia cells' exit from the cell cycle and sets them in quiescence phase, leading to their resistance against drug-induced apoptosis. $^{63,64}$ Vav molecule is a member of Vav family and is involved in signal transduction in the signaling pathway. It converts the Rac-1bound GDP to GTP and plays a role in the activation of Rac- $1 .{ }^{65}$ It is observed that Bcr/Abl fusion in chronic myeloid leukemia (CML) forms a complex with Vav, which activates Rac-1. In this way, the activation of Rac-1 will result in resistance of leukemic cells to chemotherapy drugs. 66

Angiogenesis as well as quantity of vessels is increased following increasing number of cells in BM. Therefore, the question of leukemia cell involvement in BM angiogenesis process is posed. In physiologic conditions, there is a balance between pro- and anti-angiogenic factors and when this equilibrium is disrupted, angiogenesis is decreased or increased according to dominance of stimulatory or inhibitory factors, respectively ${ }^{67}$ Angiogenesis is a process normally occurring in healthy people in specific situations and pathologically in patients with malignancy. During this process, a series of new blood vessels are formed from existing blood vessels. In BM of leukemia patients, the level of blood vessels is higher than normal individuals. The quantity of blood vessels in leukemia patients is usually referred to as microvessel density (MVD).$^{68}$ which is used as a prognostic factor associated with poor prognosis. The higher MVD, the higher disease relapse risk that is associated with lower survival rate of patients. ${ }^{69}$ Several factors are involved in angiogenesis stimulation, including granulocyte colony stimulating factor (G-CSF), platelet derived growth factor (PDGF), basic fibroblast growth factor (bFGF), and vascular endothelial growth factor (VEGF), the latter being the most important factor inducing angiogenesis. ${ }^{70}$ VEGF has six isoforms: VEGF-A, VEGF- B, VEGF-C, VEGF-D, VEGF-E, and PLGF. These isoforms bind three tyrosine kinase receptor of VEGFR-3 (Flt-4), VEGFR-2 (KDR), and VEGFR-1 (Flt-1). ${ }^{71}$ VEGFR-1 is mainly expressed on monocytes, HSCs, and leukemia cells

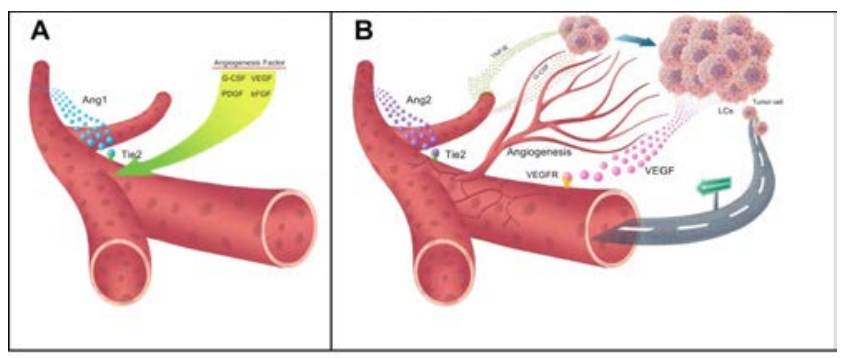

Figure 1. Function of angiogenic factors in normal and neoplastic conditions: A) in normal conditions, Ang1 binds its receptor of Tie 2 and consolidates vessel wall but in B) malignant conditions, Ang2 level is increased with an opposite function to Ang1, destabilizing and degenerating the vessel, which results in angiogenesis due to the presence of secretory VEGF factor. Blood vessels are a factor for transport of malignant cells to other sites to cause metastasis. G-CSF affects leukemia cells and causes their growth. LCs, leukemia cells; VEGFR, vascular endothelial growth factor receptor; VEGF, vascular endothelial growth factor; Ang1,2, angiopoietin1,2; PDGF, platelet derived growth factor; bFGF, basic fibroblast growth factor; G-CSF, Granulocyte colony stimulating factor; TNF- $\alpha$, Tumor necrosis factor- $\alpha$. while VEGFR-2 is detected on EC progenitors but VEGFR-3 is mostly confined to lymphatic EC. VEGF is secreted by several types of leukemia and contributes to disease progress via autocrine and paracrine pathways. In the autocrine pathway, VEGF produced by leukemia cells binds its receptor on the same leukemia cells, causing the proliferation and survival of these cells, but in the paracrine pathway, VEGF produced by leukemia cell binds its receptor on EC, resulting in angiogenesis and drug resistance. It also induces ECs to produce G-CSF, which affects the leukemia cells and leads to their proliferation. ${ }^{72,73}$ In addition to the above-mentioned VEGF function, it can be involved in angiogenesis in leukemia in association with angiopoietin (Ang). Ang is a growth factor including four isoforms of Ang-1,2,3,4 that bind a single receptor known as Tie-2. Tie-2 is a receptor tyrosine kinase expressed on ECs and HSCs. ${ }^{74}$ In normal conditions, Ang-1 consolidates ECs but Ang-2 has an opposite effect to Ang-1. It separates pericytes from EC, disintegrating EC, increasing EC exchanges and causing their loss. In leukemia, Ang-2 level is increased, which is associated with a poor prognosis. ${ }^{75}$ Despite the fact that Ang- 2 causes the loss of vessels, the presence of VEGF along with Ang-2 causes sprouting and increased angiogenesis. ${ }^{76}$ (Figure 1). VEGF-C is another growth factor of VEGF family produced by EC, which is involved in lymph angiogenesis by affecting VEGFR-3 on leukemia cells. VEGF-C is also involved in the proliferation and protection of leukemia cells against chemotherapy. ${ }^{77}$ With regard to the fact that different cells are involved in synthesis and expression of VEGF-C, measuring VEGF-C/NEGFR-3 level is not a reliable prognostic factor in leukemia. ${ }^{78}$

\section{The role of vessel in metastasis}

Approximately $10 \%$ of tumor-associated deaths are related to damages to sites where the tumor first appeared and the remaining $90 \%$ is related to tumor metastasis. Despite the high mortality rate associated with metastasis, our knowledge on biology of metastasis and the events occurring in the process of metastasis is still negligible. ${ }^{79}$ Metastasis is a process involving several steps as follows. First, the tumor cells grow and spread in their original site. Angiogenesis is simultaneously increased to provide for metabolite needs. Then, a tumor cell enters into bloodstream either directly through blood vessels or indirectly through lymphatic vessels and is thus detached from the original bulk (Figure 1). This cell should survive in bloodstream to reach another organ; therefore, it may leave the bloodstream, enter into a secondary organ, grow and proliferate and hence cause the spread of tumor. ${ }^{80}$ Since ECs form a firm barrier against a variety of cells, including tumor cells, it is necessary to make changes in this barrier to enable the passage of tumor cells for their spread. Therefore, when the tumor cells lie near blood vessels, they produce a number of factors such as VEGF, Ang2, etc. These factors affect the epithelial monolayer, disintegrate the lining and can thus pass through EC barrier. ${ }^{81,82}$ The bulk of tumor cells cause hypoxic conditions by increasing the consumption of oxygen. ${ }^{83}$ Hypoxia activates HIF-1 transcription factor, which increases the expression of angiogenesis-stimulating factors as well as growth factors, enhancing angiogenesis in tumor cell bulk. ${ }^{84} \mathrm{HIF}-1$ also induces the process of epithelial-mesenchymal transition (EMT), which leads to changes in cell morphology, including loss of cell-cell and cell-matrix adhesion that are features of metastatic cells. ${ }^{85}$ EMT is a process through which the epithelial cells gradually acquire the structure, function and markers of mesenchymal cells. These mesenchymal-like cells lose the capacity to bind and attach to extracellular matrix, which results in their mobilization and movement from their primary site to other places in the body. ${ }^{86}$ This process is observed during embryonic development, wound healing and cancer metastasis. ${ }^{87}$ Since the tumor cells are transported by bloodstream and their diffusion is dependent 
upon vessels, increased angiogenesis in tumor results in augmentation of metastasis and spread of cancer cells. ${ }^{88}$ It has been suggested that tumor endothelial cells (TECs) are involved in the survival, proliferation and metastasis of cancer cells. TECs are different from normal endothelial cells (NECs) and lack an appropriate shape and organization. ${ }^{89}$ In addition, their basement membrane is thick in some parts and shows a higher level of VEGFR1,2 expression relative to NECs. Therefore, TECs become more sensitive to the presence of VEGF, which will result in their increased proliferation. Moreover, the expression of specific markers such as stem cell antigen (Sca-1), tumor endothelial marker-8 (TEM-8), and aminopeptidase N (APN) is increased in TECs. The VEGF secreted by tumor cells activates the PI3K-AKT pathway and increases MRD-1 expression induction, which is a drug-resistance mechanism in TECs. ${ }^{90}$ TEC do not show a number of markers normally expressed by endothelial cells and secrete factors such as Biglycan. Biglycan serves as a chemoattractant causing tumor cell migration and movement through paracrine pathway. It is also produced by activated macrophages and is able to bind tumor growth factor $\beta$ (TGF- $\beta$ ), TNF$\alpha$ and bone morphogenetic protein-4. Whether or not Biglycan produced by TEC can bind these factors is unknown and could provide grounds for further investigation to elucidate this matter. ${ }^{91,92}$

\section{Discussion and future perspective}

HSCs in BM are mainly located alongside the arterioles and sinusoids. ${ }^{13}$ Sinusoids are destroyed following radiation therapy while the arterioles show resistance and HSCs are less vulnerable since they are located along arterioles and are in quiescence phase. Therefore, HSCs near arterioles begin to proliferate and differentiate following radiation to prevent pancytopenia and restore hematopoiesis. ${ }^{93}$ When leukemia cells integrate in the blood vessel walls,they secrete a series of angiogenic factors like VEGF, which result in angiogenesis as well as proliferation of leukemia cells, so that MVD is higher in leukemia patients compared with healthy subjects. On the other hand, the expression of some adhesion molecules is increased on the surface of ECs, which is involved in leukemia cell binding to Ecs. ${ }^{64,94}$ The leukemia cells orientate towards the blood vessel walls, exit from the cell cycle and enter into a state of quiescence. Therefore, ECs are tightly juxtaposed and prevent the permeation of chemotherapeutic agents into the vessel, which causes the resistance of leukemia cells to chemotherapy drugs. ${ }^{63}$ Finally, given that the angiogenic factors secreted by leukemia cells and blood vessels play an important role in angiogenesis and since the vessel walls are impervious to chemotherapy drugs, targeting factors such as VEGF and microtubules that are respectively involved in angiogenesis and integrity of vessel wall causes susceptibility of leukemia cells to chemotherapy drugs and prevents disease recurrence.

\section{Highlights}

- The role of vessels in the regulation of BM hematopoiesis.

- Role of vessels in drug resistance in leukemia.

- Chemotherapy induces changes in vessel structure.

- Neoplastic vessel facilitates the metastasis of cancer stem cells.

\section{References}

1. Schepers K, Campbell TB, Passegué E. Normal and leukemic stem cell niches: insights and therapeutic opportunities. Cell Stem Cell 2015;16:254-67.

2. Etet PFS, Vecchio L, Kamga PB, et al. Normal hematopoiesis and hematologic malignancies: role of canonical Wnt signaling path- way and stromal microenvironment. Biochim Biophys Acta 2013;1835:1-10.

3. Schmitt-Graeff AH, Nitschke R, Zeiser R. The hematopoietic niche in myeloproliferative neoplasms. Mediat Inflammat 2015;2015.

4. Seshadri M, Qu C-K. Microenvironmental regulation of hematopoietic stem cells and its implications in leukemogenesis. Curr Opin Hematol 2016;23:339-45.

5. Heissig B, Ohki Y, Sato Y, et al. A role for niches in hematopoietic cell development. Hematology 2005;10:247-53.

6. Norozi F, Shahrabi S, Hajizamani S, Saki N. Regulatory role of megakaryocytes on hematopoietic stem cells quiescence by CXCL4/PF4 in bone marrow niche. Leukemia Res 2016 [Epub ahead of print].

7. Kopp HG, Hooper AT, Avecilla ST, Rafii S. Functional heterogeneity of the bone marrow vascular niche. Ann N Y Acad Sci 2009;1176:47-54.

8. Rafii S, Butler JM, Ding B-S. Angiocrine functions of organ-specific endothelial cells. Nature 2016;529:316-25.

9. Oh M, Nör JE. The perivascular niche and self-renewal of stem cells. Front Physiol 2015;6.

10. Favaro E, Amadori A, Indraccolo S. Cellular interactions in the vascular niche: implications in the regulation of tumor dormancy. Apmis 2008;116:648-59.

11. Morrison SJ, Scadden DT. The bone marrow niche for haematopoietic stem cells. Nature 2014;505:327-34.

12. Balduino A, Mello-Coelho V, Wang Z, et al. Molecular signature and in vivo behavior of bone marrow endosteal and subendosteal stromal cell populations and their relevance to hematopoiesis. Exp Cell Res 2012;318:2427-37.

13. Kunisaki Y, Frenette PS. Influences of vascular niches on hematopoietic stem cell fate. Int J Hematol 2014;99:699-705.

14. Anthony BA, Link DC. Regulation of hematopoietic stem cells by bone marrow stromal cells. Trends Immunol 2014;35:32-7.

15. Nombela-Arrieta C, Pivarnik G, Winkel B, et al. Quantitative imaging of haematopoietic stem and progenitor cell localization and hypoxic status in the bone marrow microenvironment. Nature Cell Biol 2013;15:533-43.

16. Itkin T, Gur-Cohen S, Spencer JA, et al. Distinct bone marrow blood vessels differentially regulate haematopoiesis. Nature 2016 [Ahead of print].

17. Nagasawa T. Microenvironmental niches in the bone marrow required for B-cell development. Nature Rev Immunol 2006;6:10716.

18. Sivaraj KK, Adams RH. Blood vessel formation and function in bone. Develop 2016;143:2706-15.

19. Kusumbe AP, Ramasamy SK, Adams RH. Coupling of angiogenesis and osteogenesis by a specificvessel subtype in bone. Nature 2014;507:323-8.

20. Yamazaki S, Ema H, Karlsson G, et al. Nonmyelinating Schwann cells maintain hematopoietic stem cell hibernation in the bone marrow niche. Cell 2011;147:1146-58.

21. Zhou BO, Ding L, Morrison SJ. Hematopoietic stem and progenitor cells regulate the regeneration of their niche by secreting Angiopoietin-1. Elife 2015;4:e05521.

22. Kopp H-G, Avecilla ST, Hooper AT, Rafii S. The bone marrow vascular niche: home of HSC differentiation and mobilization. Physiology 2005;20:349-56.

23. Feng W, Madajka M, Kerr BA, et al. A novel role for platelet secretion in angiogenesis: mediating bone marrow-derived cell mobilization and homing. Blood 2011;117:3893-902.

24. Wang LD, Wagers AJ. Dynamic niches in the origination and differentiation of haematopoietic stem cells. Nature Rev Mol Cell Biol 2011;12:643-55.

25. Kumar R, Stepanek F, Mantalaris A. An oxygen transport model for human bone marrow microcirculation. Food Bioprod Process 
2004;82:105-16.

26. Sardina JL, López-Ruano G, Sánchez-Sánchez B, et al. Reactive oxygen species: are they important for haematopoiesis? Crit Rev Oncol/Hematol 2012;81:257-74.

27. Harjes U, Verfaillie C, Carmeliet P. Endothelial barrier and metabolism: new kids on the block regulating bone marrow vascular niches. Develop Cell 2016;37:210-2.

28. Jang Y-Y, SharkisSJ. A low level of reactive oxygen species selects for primitive hematopoietic stem cells that may reside in the lowoxygenic niche. Blood 2007;110:3056-63.

29. Hooper AT, Butler JM, Nolan DJ, et al. Engraftment and reconstitution of hematopoiesis is dependent on VEGFR2-mediated regeneration of sinusoidal endothelial cells. Cell Stem Cell 2009;4:263-74.

30. Johansson I, Aaltonen KE, Ebbesson A, et al. Increased gene copy number of KIT and VEGFR2 at $4 \mathrm{q} 12$ in primary breast cancer is related to an aggressive phenotype and impaired prognosis. Genes Chromosom Cancer 2012;51:375-83.

31. Wang L, Zhang W, Ding Y, et al. Up-regulation of VEGF and its receptor in refractory leukemia cells. Int $\mathrm{J}$ Clin Exp Pathol 2015;8:5282.

32. Ding L, Saunders TL, Enikolopov G, Morrison SJ. Endothelial and perivascular cells maintain haematopoietic stem cells. Nature 2012;481:45-62.

33. Kanetsky PA, Mitra N, Vardhanabhuti S, et al. Common variation in KITLG and at $5 q 31.3$ predisposes to testicular germ cell cancer. Nature Genet 2009;41:811-5.

34. Fox MF, Pontier A, Gurbuxani S, Sipkins DA. Stem cell factor expression in B cell malignancies is influenced by the niche. Leukemia Lymph 2013;54:2274-80.

35. Sonneck K, Florian S, Böhm A, et al. Evaluation of biologic activity of tryptase secreted from blast cells in acute myeloid leukemia. Leukemia Lymph 2006;47:897-906.

36. Winkler IG, Barbier V, Nowlan B, et al. Vascular niche E-selectin regulates hematopoietic stem cell dormancy, self renewal and chemoresistance. Nature Medi 2012;18:1651-7.

37. Iida A, Nakamura Y. High-resolution SNP map in the 55-kb region containing the selectin gene family on chromosome 1q24-q25. J Human Genet 2003;48:0150-4.

38. Rashidi A, Uy GL. Targeting themicroenvironment in acute myeloid leukemia. Curr Hematol Malign Report 2015;10:126-31.

39. Nogueira-Pedro A, Dias CC, Regina H, et al. Nitric oxide-induced murine hematopoietic stem cell fate involves multiple signaling proteins, gene expression, and redox modulation. Stem Cells 2014;32:2949-60.

40. Hingorani AD. Endothelial nitric oxide synthase polymorphisms and hypertension. Curr Hypertens Rep 2003;5:19-25.

41. Siripin D, Fucharoen S, Tanyong DI. Nitric oxide and caspase 3 mediated cytokine induced apoptosis in acute leukemia. Asian Pacif J Allergy Immunol 2011;29:102.

42. Ding L, Morrison SJ. Haematopoietic stem cells and early lymphoid progenitors occupy distinct bone marrow niches. Nature 2013;495:231-5.

43. Mehta NN, Li M, William D, et al. The novel atherosclerosis locus at 10q11 regulates plasma CXCL12 levels. Eur Heart J 2011:ehr091.

44. Kim J-A, Shim J-S, Lee G-Y, et al. Microenvironmental remodeling as a parameter and prognostic factor of heterogeneous leukemogenesis in acute myelogenous leukemia. Cancer Res 2015;75:222231.

45. Sison EAR, Brown P. The bone marrow microenvironment and leukemia: biology and therapeutic targeting. Exp Rev Hematol 2011;4:271-83.

46. Butler JM, Nolan DJ, Vertes EL, et al. Endothelial cells are essential for the self-renewal and repopulation of Notch-dependent hematopoietic stem cells. Cell Stem Cell 2010;6:251-64.
47. Conti V, Carabalona A, Pallesi-Pocachard E, et al. Periventricular heterotopia in $6 \mathrm{q}$ terminal deletion syndrome: role of the C6orf70 gene. Brain 2013:awt249.

48. Shutter JR, Scully S, Fan W, et al. Dll4, a novel Notch ligand expressed in arterial endothelium. Genes Develop 2000;14:1313-8.

49. Zhang J, Ma D, Ye J, et al. Prognostic impact of -like ligand 4 and Notch1 in acute myeloid leukemia. Oncol Rep 2012;28:1503-11.

50. Poulos MG, Guo P, Kofler NM, et al. Endothelial Jagged-1 is necessary for homeostatic and regenerative hematopoiesis. Cell Rep 2013;4:1022-34.

51. Röpke A, Kujat A, Gräber M, et al. Identification of 36 novel Jaggedl (JAG1) mutations in patients with Alagille syndrome. Hum Mutat 2003;21:100-.

52. Czemerska M, Pluta A, Szmigielska-Kaplon A, et al. Jagged-1: a new promising factor associated with favorable prognosis in patients with acute myeloid leukemia. Leukemia Lymph 2015;56:401-6.

53. Himburg HA, Muramoto GG, Daher P, et al. Pleiotrophin regulates the expansion and regeneration of hematopoietic stem cells. Nature Med 2010;16:475-82.

54. Li YS, Hoffman RM, Le Beau MM, et al. Characterization of the human pleiotrophin gene. Promoter region and chromosomal localization. J Biol Chem 1992;267:26011-6.

55. Du Cx, Wang L, Li Y, et al. Elevated expression of pleiotrophin in lymphocytic leukemiaCD19+ B cells. APMIS 2014;122:905-13.

56. Poulos MG, Gars EJ, Gutkin MC, et al. Activation of the vascular niche supports leukemic progression and resistance to chemotherapy. Exp Hematol 2014;42:976-86. e3.

57. Chen Y, Jacamo R, Shi Y-x, et al. Human extramedullary bone marrow in mice: a novel in vivo model of genetically controlled hematopoietic microenvironment. Blood 2012;119:4971-80.

58. Drusbosky L, Gars E, Trujillo A, et al. Endothelial cell derived angiocrine support of acute myeloid leukemia targeted by receptor tyrosine kinase inhibition. Leukemia Res 2015;39:984-9.

59. Chauncey TR, Gundacker H, Shadman M, et al. Sequential phase II Southwest Oncology Group studies (S0112 and S0301) of daunorubicin and cytarabine by continuous infusion, without and with ciclosporin, in older patients with previously untreated acute myeloid leukaemia. Br J Haematol 2010;148:48-58.

60. Bosse RC, Wasserstrom B, Meacham A, et al. Chemosensitizing AML cells by targeting bone marrow endothelial cells. Exp Hematol 2016;44:363-77. e5.

61. BraunA, Caesar NM, Dang K, Myers KA. High-resolution time-lapse imaging and automated analysis of microtubule dynamics in living human umbilical vein endothelial cells. J Visual Exp 2016:e54265-e.

62. Kupsa T, Vanek J, Vasatova M, et al. Evaluation of cytokines and soluble adhesion molecules in patients with newly diagnosed acute myeloid leukemia: the role of TNF-alpha and FLT3-ITD. Biomed Pap Med Fac Univ Palacky Olomouc Czech Repub 2016;160(1):94-9.

63. Wang J-Y, Yu P, Chen S, et al. Activation of Racl GTPase promotes leukemia cell chemotherapy resistance, quiescence and niche interaction. Mol Oncol 2013;7:907-16.

64. Cogle CR, Goldman DC, Madlambayan GJ, et al. Functional integration of acute myeloid leukemia into the vascular niche. Leukemia 2014;28:1978-87.

65. López-Lago M, Lee H, Cruz C, et al. Tyrosine phosphorylation mediates both activation and downmodulation of the biological activity of Vav. Mol Cell Biol 2000;20:1678-91.

66. Bassermann F, Jahn T, Miething C, et al. Association of Bcr-Abl with the proto-oncogene Vav is implicated in activation ofthe Rac1 pathway. J Biol Chem 2002;277:12437-45.

67. Bergers G, Benjamin LE. Tumorigenesis and the angiogenic switch. Nature Rev Cancer 2003;3:401-10.

68. AbdElAal AA, Afify RAA, Zaher AE, et al. Study ofprognostic significance of marrow angiogenesis assessment in patients with de novo 
acute leukemia. Hematol 2015;20:504-10.

69. Rabitsch W, Sperr WR, Lechner K, et al. Bone marrow microvessel density and it's prognostic significance in AML. Leukemia Lymph 2004;45:1369-73.

70. Moehler T, Ho A, Goldschmidt H, Barlogie B. Angiogenesis in hematologic malignancies. Crit Rev Oncol/Hematol 2003;45:22744.

71. Han Y, Wang X, Wang B, Jiang G. The progress of angiogenic factors in the development of leukemias. Intractable Rare Dis Res 2016;5:6.

72. Dias S, Hattori K, Heissig B, et al. Inhibition of both paracrine and autocrine VEGF/VEGFR-2 signaling pathways is essential to induce long-term remission of xenotransplanted human leukemias. Proc Natl Acad Sci 2001;98:10857-62.

73. Medinger M, Passweg J. Role of tumour angiogenesis in haematological malignancies. Swiss Med Wkly 2014;144:w14050.

74. Lee $\mathrm{C}$, Tien $\mathrm{H}, \mathrm{Hu} \mathrm{C}$, et al. Marrow angiogenesis-associated factors as prognostic biomarkers in patients with acute myelogenous leukaemia. Br J Cancer 2007;97:877-82.

75. Karakurt N, Aksu T, Koksal Y, et al. Angiopoietins in the bone marrow microenvironment of acute lymphoblastic leukemia. Hematology 2016:1-7.

76. Koh GY, Kim I, Kwak HJ, et al. Biomedical significance of endothelial cell specific growth factor, angiopoietin. Exp Mol Med 2002;34:1-11.

77. Hua K-T, Lee W-J, Yang S-F, et al. Vascular endothelial growth factor- $\mathrm{C}$ modulates proliferation and chemoresistance in acute myeloid leukemic cells through an endothelin-1-dependent induction of cyclooxygenase-2. Biochim Biophys Acta 2014;1843:387-97.

78. Liersch R, Schliemann C, Bieker R, et al. Expression of VEGF-C and its receptor VEGFR-3 in the bone marrow of patients with acute myeloid leukaemia. Leukemia Res 2008;32:954-61.

79. García-Román J, Zentella-Dehesa A. Vascular permeability changes involved in tumor metastasis. Cancer Lett 2013;335:259-69.

80. Chambers A, Groom A, MacDonald I. Dissemination and growth of cancer cells in metastatic sites. Nat Rev Cancer 2002;2:563.

81. Huang Y, Song N, Ding Y, et al. Pulmonary vascular destabilization in the premetastatic phase facilitates lung metastasis. Cancer Res 2009;69:7529-37.
82. Montes-Sánchez D, Ventura JL, Mitre I, et al. Glycosylated VCAM-1 isoforms revealed in 2D western blots of HUVECs treated with tumoral soluble factors of breast cancer cells. BMC Chem Biol 2009;9:1.

83. Masson N, Ratcliffe PJ. Hypoxia signaling pathways in cancer metabolism: the importance of co-selecting interconnected physiological pathways. Cancer Metab 2014;2:1.

84. Michiels C, Arnould T, Remacle J. Endothelial cell responses to hypoxia: initiation of a cascade of cellular interactions. Biochim Biophys Acta 2000;1497:1-10.

85. Rankin EB, Giaccia AJ. Hypoxic control of metastasis. Science 2016;175:352 80.

86. Pasquier J, Abu-Kaoud N, Al Thani H, Rafii A. Epithelial to mesenchymal transition in a clinical perspective. J Oncology $2015 ; 2015$.

87. Vaquero J, Guedj N, Clapéron A, et al. Epithelial-mesenchymal transition in cholangiocarcinoma: from clinical evidence to regulatory networks. J Hepatol 2016 [Ahead of print].

88. Folkman J. Role of angiogenesis in tumor growth and metastasis. Semin Oncology 2002;29:15-8.

89. Ohga N, Hida K, HidaY, et al. Inhibitory effects of epigallocatechin 3 gallate, a polyphenol in green tea, on tumor associated endothelial cells and endothelial progenitor cells. Cancer Sci 2009;100:1963-70.

90. Matsuda K, Ohga N, Hida Y, et al. Isolated tumor endothelial cells maintain specific character during long-term culture. Biochem Biophys Res Commun 2010;394:947-54.

91. Maishi N, Ohba Y, Akiyama K, et al. Tumour endothelial cells in high metastatic tumours promote metastasis via epigenetic dysregulation of biglycan. Sci Rep 2016;6.

92. Chang YS, di Tomaso E, McDonald DM, et al. Mosaic blood vessels in tumors: frequency of cancer cells in contact with flowing blood. Proc Natl Acad Sci 2000;97:14608-13.

93. Poulos MG, Crowley MJ, Gutkin MC, et al. Vascular platform to definehematopoietic stem cell factors and enhance regenerative hematopoiesis. Stem Cell Rep 2015;5:881-94.

94. Cogle CR, Bosse RC, Brewer T, et al. Acute myeloid leukemia in the vascular niche. Cancer Lett 2016;380:552-60. 